\title{
Chronic postoperative pain: pathophysiology, risk factors and prevention*
}

\author{
Dor crônica pós-operatória: fisiopatologia, fatores de risco e prevenção
}

Eduardo Jun Sadatsune ${ }^{1}$, Plínio da Cunha Leal ${ }^{1}$, Jefferson Clivatti², Rioko Kimiko Sakata ${ }^{3}$

*Received from the Anesthesiology, Pain and Intensive Care Department, Federal University of São Paulo (UNIFESP). São Paulo, SP.

\section{SUMMARY}

BACKGROUND AND OBJECTIVES: Chronic postoperative pain (CPOP) prevalence is high, and is manifested both after minor and major surgeries. This subject has been increasingly studied. This study aimed at describing major aspects of this syndrome.

CONTENTS: CPOP mechanisms, risk factors for its development, prevention and pain treatments are described. CONCLUSION: CPOP impacts patients' quality of life, is difficult to treat and the best approach is to prevent it. With a better understanding of pathophysiological bases for perpetuation of pain after a surgical procedure and of risk factors, new treatment options are appearing. The real benefits of preventive drugs are being increasingly studied. To prevent pain, surgical teams and patients have to be aware of the risks of each procedure, not only in the immediate postoperative period but also in the long run.

Keywords: Chronic pain, Postoperative period, Prevention, Risk factors.

\section{RESUMO}

JUSTIFICATIVA E OBJETIVOS: A prevalência da dor crônica pós-operatória (DCPO) é grande, acometendo tanto cirurgias de pequeno porte como as de

1. Third year Resident in Anesthesiology, Federal University of São Paulo (UNIFESP). São Paulo, SP, Brazil.

2. Professor of Anesthesiology, Federal University of São Paulo (UNIFESP). São Paulo, SP, Brazil.

3. Associate Professor and Coordinator of the Pain Sector, Federal University of São Paulo (UNIFESP). São Paulo, SP, Brazil.

Correspondence to:

Rioko Kimiko Sakata, MD

Rua Três de Maio 61/51 - Vila Clementino

04044-020 São Paulo, SP.

Fone: 55 (11) 5576-4069

E-mail: riokoks.dcir@epm.br grande porte. Esse tema vem sendo estudado cada vez mais. O objetivo deste estudo foi descrever aspectos importantes sobre essa síndrome.

CONTEÚDO: Descrevem-se os mecanismos da DCPO, os fatores de risco para seu desenvolvimento, a prevenção e o tratamento da dor.

CONCLUSÃO: A DCPO afeta a qualidade de vida dos pacientes, é de difícil tratamento sendo a medida mais eficaz a sua prevenção. Com o melhor entendimento das bases fisiopatológicas da perpetuação da dor após um procedimento cirúrgico e dos fatores de risco, novas opções para o seu tratamento estão surgindo. Os reais benefícios da utilização de fármacos usados de forma preventiva estão sendo cada vez mais estudados. Na prevenção da dor as equipes cirúrgicas e os pacientes necessitam estar atentos aos riscos de cada procedimento, não somente no perioperatório imediato, mas também em longo prazo.

Descritores: Dor crônica, Fatores de riscos, Pós-operatório, Prevenção.

\section{INTRODUCTION}

Chronic postoperative pain (CPOP) has been neglected for a long time by the medical community. Currently, CPOP is being increasingly studied with important evolution.

Although scarcely documented in the literature, CPOP incidence is highly variable and appears both after highly complex surgeries, such as thoracotomy, and after simplest ones, such as inguinal hernia and vasectomy. After surgery, between $5 \%$ and $80 \%$ of patients evolve to chronic pain, especially after procedures causing nervous injury ${ }^{1}$. The incidence after limb amputation is from $30 \%$ to $81 \%$; after thoracotomy and inguinal hernia, from $11.5 \%$ to $47 \%$; after cholecystectomy from $3 \%$ to $56 \%^{2}$; after breast cancer surgery from $10 \%$ to $50 \% \%^{2,3}$; after vasectomy $15 \%^{4}$; after C-section from $6 \%$ to $18 \%$ and after vaginal delivery from $4 \%$ to $10 \%{ }^{5}$. 
The broad variation of incidence may be associated to several definitions used for CPOP in different studies ${ }^{6,7}$. Macrae defines CPOP as pain after surgical procedure lasting for at least two months, unrelated to pre-existing pain and without other defined causes (such as, for example, infection $)^{8}$. Other causes for such variability in the incidence of CPOP are evaluation and interpretation of types of painful syndromes and different study designs $^{7}$. Chart 1 describes some examples of CPOP. nociceptive stimulation transmission and recruits nonnociceptive stimulations to the pain pathway. Kinase-C protein and nitric oxide (NO) activation contributes to increase the excitability of nociceptive neurons 9 . NO induces sensitization of nocireceptors, increasing prostaglandin E2 release, inhibiting the action of endogen antinociceptive substances on peripheral receptors and directly acting on nociceptors. Central sensitization is partially mediated by NMDA receptor activation with

Chart 1- Examples of surgical procedures and evolution to chronic pain

\begin{tabular}{ll}
\hline Limb amputation & Stump pain, phantom limb pain, myofascial pain \\
\hline Thoracotomy & Intercostal neuritis, myofascial syndrome, costochondritis \\
\hline Mastectomy & Traumatic neuritis, myofascial syndrome, frozen shoulder, lymphedema \\
\hline Spine & Arachnoiditis, myofascial syndrome \\
\hline Myocardial revascularization & Traumatic neuritis, costochondritis, myofascial syndrome \\
\hline Limbs & Complex regional pain syndrome, myofascial syndrome, frozen shoulder \\
\hline Hernioplasty & Traumatic neuritis \\
\hline
\end{tabular}

\section{CHRONIC POSTOPERATIVE PAIN MECHANISMS}

Chronic postoperative pain mechanisms are complex and not fully understood. Different mechanisms are responsible for different painful syndromes, even in a single type of surgery ${ }^{5}$.

There is the neuroplasticity process, which is complex and in constant change in membrane excitability, reducing inhibitory mechanisms and increasing the excitatory synaptic efficacy ${ }^{9}$. Surgical stimulation, which starts with the incision, is maintained throughout the postoperative inflammatory process and finishes only with surgical healing, causes the neuroplasticity process $^{6}$. There are two types of neuroplasticity: peripheral and central. Peripheral neuroplasticity is responsible for local hyperexcitability of high threshold peripheral nociceptive terminations and is caused by inflammatory mediators released by injured tissues or inflammatory cells, by the activation of intracellular cascades with lower threshold and there may be pain perception with a weaker stimulation. In central neuroplasticity there is synaptic change of the spinal cord with amplification of pain signal ${ }^{10}$. A peripheral nociceptive stimulation activates intracellular kinases pathway at the spinal cord dorsal horn changing ionic channels flow and the density of receptors and neurotransmitters. Central sensitization increases activity and density of AMPA and NMDA receptors, leading to a post-synaptic hyperexcitability. The increase of glutamatergic synapses in the spinal cord dorsal horn reinforces subsequent production of $\mathrm{NO}^{11}$. After central sensitization induction, responsiveness of neurons is increased and even those which normally have ineffective synapse for stimulations, inoculate and activate neuronal pain transmission ${ }^{10}$.

The mechanism of postoperative pain propagation by direct peripheral nervous injury is highly variable. The injury of major nerves located in the surgical field of most procedures is probably a pre-requisite for the development of $\mathrm{CPOP}^{10}$. In a thoracotomy study with and without intercostal nerve protection, pain evaluation after 2 to 7 days has shown a lower pain score in patients who had their intercostal nerve protected, however this was not observed one month after surgical procedure ${ }^{15}$. In a different study, authors carried out an electrophysiological study in patients submitted to thoracotomy before and three months after procedure. They have not observed association between intercostal nerve injury and pain or sensitivity change after three months of follow-up ${ }^{13}$.

\section{Risk factors}

Several factors contribute to chronic postoperative pain $^{14-17}$.

- Preoperative factors: pain lasting more than one month, psychological, genetic and diabetes mellitus;

- Intraoperative factors: nervous injury, incision site and type, duration, repeated surgery and complications;

- Postoperative factors: pain intensity, pain duration, immobilization and inactivity. 
Risk factors for the development of CPOP are variable and may be individual and surgical. Most important factors are pain intensity and nervous injury. Other associated factors are: female gender and psychological factors (anxiety, depression, catastrofization, fear, passive behavior and secondary gain).

Age

Younger people run less risk of developing CPOP after thoracotomy ${ }^{18,19}$, breast cancer ${ }^{3}$ and elective abdomina ${ }^{20}$ surgery.

\section{Genetic}

It seems that changes in the GTP-cyclohydrolase gene, seen in approximately $15 \%$ of the population, is associated to protection against neuropathic pain and painful perception decrease. GTP-cyclohydrolase regulates tetrahydropiopterin production, which is an essential co-factor for the production of catecholamines, serotonin and nitric oxide, modulators of neuropathic and inflammatory pain ${ }^{21}$. There is a family history report on hypertension with decreased pain perception, which may be associated to mitochondrial DNA $^{22}$, factor still very controversial ${ }^{23}$. Genetic polymorphism of catecholamine-O-methyltransferase gene is associated to the impact on pain perception and on the risk of developing CPOP ${ }^{24}$.

\section{Perioperative pain}

Severe pain immediately after surgery is a significant risk factor for CPOP. There are evidences that acute pain treatment not only accelerates surgical recovery, but also decreases the risk for pain persistence ${ }^{25}$. Acute post $\mathrm{C}$-section pain is an independent risk factor for the development of $\mathrm{CPOP}^{26}$. Pain after and before amputation is a significant predictor of chronic pain intensity, which suggests that the risk for postamputation chronic pain is higher in individuals with higher pain scores in all those moments ${ }^{27}$. Pain immediately before amputation influences the development of stump and phantom pain. However, a study has not associated acute pain to CPOP six months after total knee artroplasty ${ }^{28}$.

\section{Psychosocial}

Anxiety is a major factor for pain intensity. Anxious patients are in general hypersensitive to stimulation and psychologically more reactive. Depression is related to higher postoperative pain intensity, which makes us consider that the improvement of such symptoms and of postoperative pain may interrupt pain chronicity process $^{20}$. Fear of surgical consequences in the long run was associated to more pain, worse global recovery and quality of life; however optimism was associated to better recovery and quality of life ${ }^{29}$.

\section{Surgical}

Patients submitted to thoracotomy with different access pathways and closure techniques have evolved differently ${ }^{18}$. Surgical procedures lasting more than 3 hours are associated to increased risk for developing CPOP; however, longer surgeries are probably more complex and risky ${ }^{29}$. Change in inguinal sensitivity one year after surgery depends on the surgical technique ${ }^{19}$. Different techniques for different procedures evolve in different ways to CPOP. Video thoracoscopy poses a lower risk as compared to conventional thoracoscopy. Risk is higher for breast cancer surgery with axillary exploration ${ }^{2}$.

\section{Prevention}

Prevention can be obtained as follows:

- Less traumatic surgery;

- Avoid nervous injury;

- Diabetes mellitus control;

- Preoperative analgesia;

- Perioperative analgesia;

- Postoperative analgesia;

- Early mobilization;

- Improvement of venous return;

- Avoid compressing structures.

Early and late postoperative pain prevention is a major challenge for anesthesiologists and surgeons, since it is difficult to treat CPOP. In an attempt to improve its perioperative control and to estimate postoperative pain, more and more studies are being developed every day to implement effective measures and to minimize unnecessary and inadequate surgeries ${ }^{3}$. Postoperative pain is where the physician may influence the most ${ }^{3}$.

CPOP prevention should be performed not only by the anesthesiologist, but also by surgical teams. Patients submitted to surgical procedures should be aware of the risk of developing CPOP, since its incidence is high. Each elective surgical procedure should be carefully evaluated, analyzing benefits and risks. The surgical team shall know the different surgical techniques to which patients may be submitted, being able to choose, when possible, the technique exposing patients to the lowest risk of de- 
veloping CPOP. Carefully dissection of the surgical field avoiding nervous injuries and decreasing local inflammatory process and less invasive techniques may be strategies to prevent pain ${ }^{10}$.

A probability scale of the risk for developing CPOP was developed mentioning as some predictors age, gender, preoperative pain, type of surgery, incision size and level of anxiety, among others. It was validated for inpatients and outpatients and has good correlation with the development of acute postoperative pain $^{30}$. Since the presence of acute postoperative pain is associated to the risk of developing chronic pain, if we identify potential risk patients, more and more preventive measures, such as adequate and intensive treatment of pain throughout the perioperative period, may be performed to block CPOP development.

\section{Treatment of pain}

Treatment may be achieved with drugs, physical measures and blocks ${ }^{17}$. Drugs used are: anti-inflammatory drugs, paracetamol, dipirone, opioids, anticonvulsants, antidepressants, neuromuscular blocker, clonidine, ketamine and lidocaine. Several blocks may be performed by epidural, intra-articular, in plexus, nerve or infiltration drug injection. Physical measures include: mobilization, kinesiotherapy, desensitization, active movements and orthesis.

Preventive analgesia may be induced, which is the treatment started before surgery to prevent physical consequences of nociceptive transmission to central neuroplasticity. Similar treatment, when used before surgery has potential to be more effective than after the beginning of incision (preemptive analgesia) ${ }^{31}$.

Gabapentin and pregabalin are substances analog to GABA (gamma-aminobutyric acid) neurotransmitter, but do not bind to gabaergic receptors. Gabapentinoids bind to a sub-unit of voltage-dependent calcium channels of pre-synaptic neurons causing changes in the conformation with inhibition of abnormal neuronal activity, decreasing glutamate, norepinephrine, $\mathrm{P}$ substance and other neurotransmitters release, changing the neuroplasticity cascade. The prophylactic use of pregabalin decreases protein expression of calcium channel in the spinal cord, which is correlated to increased nociception and allodynia ${ }^{32}$. Gabapentin in single dose one hour before surgical procedure (herniorrhaphy and hysterectomy), decreased the risk and intensity of chronic pain in a 6-month follow-up ${ }^{33,34}$. It has also been observed that ketamine ${ }^{34}$ and gabapentin decreased postoperative opioid consumption ${ }^{33,35}$. A study with rats has shown that perineural lidocaine infiltration decreased neuropathic pain after sciatic nerve compression ${ }^{36}$.

A study evaluating three analgesic methods for patients submitted to thoracotomy has observed that patients with preoperative epidural block with bupivacaine and morphine presented less pain six months later as compared to patients with epidural block analgesia after the procedure and those with venous morphine analgesia ${ }^{37}$.

A metanalysis including randomized double-blind clinical trials of several surgical procedures about preemptive analgesia and evaluating acute and chronic pain has observed that the use of venous non-hormonal opioid anti-inflammatory drugs and N-MethylD-Aspartate receptors antagonists did not show preemptive effects ${ }^{38}$.

It seems that multimodal analgesia with the association of drugs and techniques is more adequate to treat pain and decreases side effects. It should be done preventively and with enough duration to prevent central sensitization by previous pain, surgical trauma and by postoperative inflammation. However, adequate studies are needed for a better evaluation of chronic postoperative pain syndromes.

\section{CONCLUSION}

Chronic postoperative pain is a morbidity of high incidence and affects quality of life of patients, although very often it is neglected by the medical team. CPOP is difficult to treat being prevention the most effective measure. With a better understanding of pathophysiological bases for postoperative pain perpetuation and of risk factors, new options to treat pain are appearing. The real benefits of preventive drugs are being increasingly studied. To prevent pain, surgical teams and patients should be aware of the risks of each procedure, not only in the immediate postoperative period, but also in the long run.

\section{REFERENCES}

1. Yung PS, Hung LK, Tong CW, et al. Carpal tunnel release with a limited palmar incision: clinical results and pillar pain at 18 months follow-up. Hand Surg 2005;10(1):29-35.

2. Perkins FM, Kehlet H. Chronic pain as an outcome of surgery. A review of predictive factors. Anesthesiology 2000;93(4):1123-33. 
3. Fecho K, Miller NR, Merritt SA, et al. et al. Acute and persistent postoperative pain after breast surgery. Pain Med 2009;10(4):708-15.

4. Leslie TA, Illing RO, Cranston DW, et al. The incidence of chronic scrotal pain after vasectomy: a prospective audit. BJU Int 2007;100(6):1330-3.

5. Vermelis JM, Wassen MM, Fiddelers AA, et al. Prevalence and predictors of chronic pain after labor and delivery. Curr Opin Anaesthesiol 2010;23(3):295-9.

6. Gerbershagen HJ, Özgür E, Dagtekin O, et al. Preoperative pain as a risk factor for chronic post-surgical pain - six month follow-up after radical prostatectomy. Eur J Pain 2009;13(10):1054-61.

7. Macrae WA. Chronic post-surgical pain: 10 years on. Br J Anaesth. 2008;101(1):77-86.

8. Macrae WA. Chronic pain after surgery. Br J Anaesth 2001;87(1):88-98.

9. Latremoliere A, Woolf CJ. Central sensitization: a generator of pain hypersensitivity by central neural plasticity. J Pain 2009;10(9):895-926.

10. Kehlet H, Jensen TS, Woolf CJ. Persistent postsurgical pain: risk factors and prevention. Lancet 2006;367(9522):1618-25.

11. Burke S, Shorten GD. When pain after surgery doesn't go away. Biochem Soc Trans 2009;37(Pt 1):318-22.

12. Yan $\mathrm{S}, \mathrm{Wu} \mathrm{N}$, Xiong $\mathrm{HC}$, et al. Effect of bilateral intercostals nerve protection on post-thoracotomy pain relief: a prospective single-blinded randomized study. Zhonghua Yi Xue Za Zhi 2008;88(9):597-601.

13. Maguire MF, Latter JA, Mahajan R, et al. A study exploring the role of intercostal nerve damage in chronic pain after thoracic surgery. Eur J Cardiothorac Surg 2006;29(6):873-9.

14. Wildgaard K, Ravn J, Kehlet H. Chronic post-thoracotomy pain: a critical review of pathogenic mechanisms and strategies for prevention. Eur J Cardiothorac Surg 2009;36(1):170-80.

15. Brandsborg B, Dueholm M, Nikolajsen L, et al. A prospective study of risk factors for pain persisting 4 months after hysterectomy. Clin J Pain 2009;25(4):263-8.

16. Akkaya T, Ozkan D. Chronic post-surgical pain. Agri 2009;21(1):1-9.

17. Hompes R, Vansteenkiste F, Pottel H, et al. Chronic pain after Kugel inguinal hernia repair. Hernia 2008;12(2):127-32.

18. Sakakura N, Usami N, Taniguchi T, et al. Assessment of long-term postoperative pain in open thoracotomy patients: pain reduction by the edge closure technique. Ann Thorac Surg 2010;89(4):1064-70.

19. Kristensen AD, Pedersen TA, Hjortdal VE, et al.
Chronic pain in adults after thoracotomy in childhood or youth. Br J Anaesth 2010;104(1):75-9.

20. Caumo W, Schmidt AP, Schneider CN, et al. Preoperative predictors of moderate to intense acute postoperative pain in patients undergoing abdominal surgery. Acta Anaesthesiol Scand 2002;46(10):1265-71. 21. Tegeder I, Costigan M, Griffi n RS, et al. GTP cyclohydrolase and tetrahydrobiopterin regulate pain sensitivity and persistence. Nat Med 2006;12(11): 1269-77.

22. France CR, Taddio A, Shah VS, et al. Maternal family history of hypertension attenuates neonatal pain response. Pain 2009;142(3):189-93.

23. McCubbin JA. Prenatal maternal stress hormones, risk for hypertension, and the neonatal pain response. Pain 2009;142(3):173-4.

24. Diatchenko L, Slade GD, Nackley AG, et al. Genetic basis for individual variations in pain perception and the development of a chronic pain condition. Hum Mol Genet 2005;14(1):135-43.

25. Poleshuck EL, Katz J, Andrus CH, et al. Risk factors for chronic pain following breast cancer surgery: a prospective study. J Pain 2006;7(9):626-34.

26. Sng BL, Sia AT, Quek K, et al. Incidence and risk factors for chronic pain after caesarean section under spinal anaesthesia. Anaesth Intensive Care 2009;37(5):748-52.

27. Hanley MA, Jensen MP, Smith DG, et al. Preamputation pain and acute pain predict chronic pain after lower extremity amputation. J Pain 2007;8(2):102-9.

28. Clarke H, Kay J, Mitsakakis N, et al. Acute pain after total hip arthroplasty does not predict the development of chronic postsurgical pain 6 months later. J Anesth 2010;24(4):537-43.

29. Peters ML, Sommer M, de Rijke JM, et al. Somatic and psychologic predictors of long-term unfavorable outcome after surgical intervention. Ann Surg 2007;245(3):487-94.

30. Schäfer M. Opioid/non-opioid drug combinations. An update review. IASP. Pain 2002;395-9.

31. Dahl JB, Møiniche S. Pre-emptive analgesia. Br Med Bull 2004;71:13-27.

32. Tuchman M, Barrett JA, Donevan S, et al. Central sensitization and $\mathrm{Ca}(\mathrm{V})$ alpha(2)delta ligands in chronic pain syndromes: pathologic processes and pharmacologic effect. J Pain 2010;11(12):1241-9.

33. Sen H, Sizlan A, Yanarates O, et al. A comparison of gabapentin and ketamine in acute and chronic pain after hysterectomy. Anesth Analg 2009;109(5):1645-50.

34. Sen H, Sizlan A, Yanarates O, et al. The effects of gabapentin on acute and chronic pain after inguinal 
herniorrhaphy. Eur J Anaesthesiol 2009;26(9):772-6. 35. Clivatti J, Sakata RK, Issy AM. Review of the use of gabapentin in the control of postoperative pain. Rev Bras Anestesiol 2009;59(1):87-98.

36. Batista LM, Batista IM, Almeida JP, et al. Preemptive analgesic effect of lidocaine in a chronic neuropathic pain model. Arq Neuropsiquiatr 2009;67(4):1088-92.

37. Sentürk M, Ozcan PE, Talu GK, et al. The effects of three different analgesia techniques on long-term postthoracotomy pain. Anesth Analg 2002;94(1):11-5.

38. Møiniche S, Kehlet H, Dahl JB. A qualitative and quantitative systematic review of preemptive analgesia for postoperative pain relief: the role of timing of analgesia. Anesthesiology 2002;96(3):725-41.

Presented in October 23, 2010.

Accepted for publication in March 01, 2011. 